\title{
Dance-based Exercise Therapy for People with Arthritis: An Update and Commentary
}

\section{Ray Marks}

School of Health Sciences and Health Professions, City University of New York, York College and Department of Health and Behavior Studies, Columbia University, Teachers College, New York, USA

"Corresponding author: Ray Marks, School of Health Sciences and Health Professions, City University of New York, York College and Department of Health and Behavior Studies, Columbia University, Teachers College, New York, USA, Tel: 212-678-3445; E-mail: rm2262@columbia.edu

Received date: July 08, 2016; Accepted date: August 04, 2016; Published date: August 10, 2016

Copyright: (c) 2016 Marks R. This is an open-access article distributed under the terms of the Creative Commons Attribution License, which permits unrestricted use, distribution, and reproduction in any medium, provided the original author and source are credited.

\section{Background}

Arthritis, a broad term used to describe more than 100 different health conditions that result in considerable physical disability, is very challenging to treat effectively, regardless of disease type. This brief review revisits the research base concerning the use of dance-based therapeutic exercises as a possible adjunct for ameliorating arthritis. The goal was to provide an overview of the potential of this form of therapy for arthritis patients as well as health professionals working with this population.

It is well established that arthritis in any form is a chronic unrelenting illness, which often waxes and wanes, and is generally incurable, and frequently progressive. Among the multiplicity of day to day problems experienced by sufferers are an increasingly limited activity tolerance, activity challenges due to physical impairments, depression, anxiety, excessive fatigue, and pain and inflammation. With few treatment options, and a diminishing exercise capacity, regular exercise participation, which can counter or attenuate most of the problems mentioned above is potentially even more crucial for this patient group, than it is for healthy adults for purposes of maintaining optimal wellbeing.

Yet, physical activity participation among people with arthritis is often highly challenging in the face of pain, joint inflammation, joint instability, muscle weakness and atrophy, limited cardiovascular capacity, and depression and/or anxiety, among other debilitating symptoms and disease correlates. Moreover, many people with some form of arthritis have comorbid health conditions, that preclude partaking in some forms of regular physical activities at levels prescribed for healthy adults.

\section{Dance Therapy}

Dance-based therapy, a form of exercise combining structured and unstructured movements is an intervention strategy shown to be beneficial in terms of alleviating long-lasting and chronic pain, improving life quality, and overcoming physical limitations, disability, and mental health status among older adults [1-4]. Although potentially useful as a pleasurable aerobic activity for purposes of minimising arthritis disability and dependence and improving life quality [5], the use of dance-based therapy is not widely discussed in the related literature in the context of treating one or more arthritic conditions.

\section{Objective}

The goal of this brief review was to examine the research that specifically discusses the application of dance therapy for people with arthritis as regards its safety and efficacy. A further goal was to use this data to provide clinicians with information about this form of therapy and whether it is safe for their clients to pursue this or not. The benefits of dance therapy were examined to specifically ascertain if this approach is likely to heighten the life quality of the individual with arthritis, regardless of joint status. All relevant studies on this topic located in PUBMED and Academic Search Complete from 1980-2016 using the key terms arthritis and dance-based exercise or therapy published in English were reviewed.

\section{Results}

Although there are a limited number of scientific reports, and very few recent reports published in the last five years, dance therapy heightens the benefit of patient enjoyment in exercise participation [5], as well as in fostering improvements in joint range of motion [5], weight reduction [6], a decrease in the extent of aversive disease symptoms [7], improvements in muscle strength [7], reductions in the severity of anxiety and depression [8], as well as a heightened sense of well-being [9].

In this regard, Van Deusen and Harlow [5] who integrated a movement program based on Tai-Chi found the initiative was beneficial for adults with rheumatoid arthritis as far as joint range of motion measures at the post-test 4 months after completing the program were concerned. Reports of enjoyment were higher for the group pursuing the dance program than controls with similar characteristics at baseline.

Perlman et al. [10] who examined the efficacy of a 16 week dance therapy class among a single group of 43 subjects with rheumatoid arthritis found dance exercise participation had no deleterious effects on disease activity. Moreover, physician-assessed articular pain and swelling decreased significantly, as did 50-foot walk time, pain on two validated self-reports, as well as depression. Participants also reported significant improvements in lower extremity function, and changes in vigor and fatigue approached significance. Perceptions of general health as well as four of five quality of life indices improved significantly. Thus, contrary to common beliefs held at that time, this study showed that dance based exercise when combined with education and other exercise forms had the potential to objectively reduce the disability and improve the perceived life quality of the individual with rheumatoid arthritis-commonly the most disabling form of arthritis, and those with higher attendance scores tended to experienced greater pain reduction, were less hampered by arthritis, and less aware of arthritis discomfort.

A further study by Noreau et al. [11] similarly found a dance based exercise program for rheumatoid arthritis patients with moderate 
Page 2 of 3

disability to be efficacious. In this comparative study, the outcomes of 19 patients who participated in a 12-week program, conducted twice weekly, were compared to a control sample who did not participate. After 12 weeks, it was shown that dance group members collectively improved their aerobic power, and there was a decline in the number of painful joints, and pain scores. Depression, anxiety and fatigue all improved and aerobic capacity improved only in the dance therapy group.

Similarly, Moffett et al. [12] found a modified dance-based exercise program to be feasible as well as efficacious even for those persons with rheumatoid arthritis and severe functional disability, who were able to improve their walking ability. The same authors also recounted a prior report [13] concerning the outcome of an 8-week long period of dance-based exercises conducted twice weekly by a physical and occupational therapist for 10 cases of rheumatoid arthritis with advanced or Functional Class III disease with respect to health status, medication usage, joint pain and swelling, cardiorespiratory fitness, activities of daily living, and psychological state where there dance participation yielded no notable deleterious effects on their health status. Moreover, four subjects showed improvements in their cardiorespiratory levels, swelling index scores improved, in addition to their self-paced walking speed, and positive changes in anxiety, depression, and fatigue were observed. The researchers reported many participants recounted an increased motivation for exercising owing to the nature of the program's structure, supervision availability, its peer group approach, as well as its approach that adapted the activities to the individual's health condition.

In sum, despite the paucity of the related reports, and the lack of any reports that focus on osteoarthritis, the most common form of arthritis, the reports documented in this review consistently reveal positive outcomes on a number of important disease-associated outcomes for dance-based therapeutic exercise as applied to people with arthritis, even when the condition is severe or advanced. In addition, the weight of the evidence points to the ability of dance therapy to safely alleviate the magnitude of arthritis disability, regardless of joint status, and to positively impact some of the many disease related problems experienced by people with arthritis as outlined in Box 1. Of specific clinical importance to people with arthritis of the lower extremities is supportive evidence provided by biomechanical evaluations of dance showing evidence of postural control post-training $[14,15]$. As well, those with depression may be especially assisted [16], stress may be reduced [17], as may inattention [15], and consequently these patients may be more effective selfmanagers and have improved outlooks that are essential to their wellbeing.

Indeed, because dance is a pleasurable activity as well as a socially desirable activity for most people, the reported psychological benefits, including neuro-cognitive executive function [18] may encourage and motivate people with arthritis to participate, as well as adhere to, exercise participation over the long-term. This is very crucial given that most patients with arthritis will fail to participate in activities perceived as difficult and painful, especially if the activity worsens their joint pain. In contrast, among the many potential benefits of dancebased exercise are improvements in body composition and disease impact [19], muscle strength capacity [20], falls risk levels [21], postural stability [22], and pain [19,23], as well as balance and walking ability [24]. In addition to all these benefits, exercise benefits immune system functioning, a highly important source of pathology in inflammatory arthritis [25] (Table 1).

\begin{tabular}{|l|}
\hline Arthritis self-efficacy \\
\hline Increased aerobic capacity \\
\hline Improved balance \\
\hline Improved fitness \\
\hline Improved flexibility \\
\hline Improved functional ability \\
\hline Improved immune system functioning \\
\hline Improved general health status \\
\hline Improved mood state \\
\hline Improved motivation for exercising \\
\hline Improved muscle strength \\
\hline Improved muscle tone \\
\hline Improved posture \\
\hline Improved proprioception \\
\hline Improved quality of life \\
\hline Improved vitality \\
\hline Improved walking ability \\
\hline Reduced pain \\
\hline Reduced stress levels \\
\hline Reduced falls risk \\
\hline Reduced fatigue \\
\hline Weight reduction \\
\hline
\end{tabular}

Table 1: Specific outcomes of dance-based therapy that could promote well-being among people with arthritis.

\section{Conclusion}

In light of the favorable outcomes reported in the literature noted above, and in recognition of the magnitude of the public health problem associated with arthritis and the likelihood of these diseases becoming more prevalent-rather than less prevalent as society ages-it is concluded that further research on the role of dance-based therapy for encouraging long-term physical activity participation among people with arthritis is justified and may prove of considerable utility. We also conclude that dance can be applied safely and effectively for people with arthritis, but would urge researchers to undertake more comparative studies to better discern what forms of dance, as well as what dosages, yield optimal results. More research on samples other than rheumatoid arthritis are also encouraged, as are future efforts to examine whether dance related weight-bearing exercises can help offset the risk of osteoporosis, and excess comorbid conditions, such as cardiac disease, obesity, and high blood pressure, along with negative immune system effects.

Meantime, it appears dance-therapy may be a useful adjunctive strategy for reducing the enormous burden arthritis places on society, 
while assisting individuals afflicted with one or more of these debilitating conditions to acquire a better life quality. We thus strongly recommend health professionals not overlook the potential widereaching physical and psychological benefits of carefully planned and monitored dance-based therapy for optimizing the health of their clients with arthritis. Indeed, the combined effects of dance therapy and education may not only provide significant relief for many from the painful symptoms of arthritis, but may do this without the damaging side effects of many other forms of intervention, such as opiate medications and others. Encouraging dance that is not injurious, but is enjoyable, and does not require expensive equipment, and is portable, may permit many patients to adhere more ably to consistent physical activity practices, shown to yield a higher life quality with better function than an inactive life style. In this regard, increasing evidence suggests those with comorbid diseases such as cardiac disease, those who are depressed, those who are very weak and fatigued, those who are overweight, and those with poor balance capacity may be especially benefited.

\section{References}

1. Bajaj T, Vohra SS (2011) Therapeutic implications of dance. Amity Journal of Applied Psychology 2: 54-68.

2. Bräuninger I (2012) The efficacy of dance movement therapy group on improvement of quality of life: a randomized controlled trial. Arts in Psychotherapy 39: 296-303.

3. Guzmán-García AA, Hughes JC, James IA, Rochester LL (2013) Dancing as a psychosocial intervention in care homes: a systematic review of the literature. International Journal of Geriatric Psychiatry 28: 914-924.

4. Horowitz S (2013) The healing power of music and dance. Alternative \& Complementary Therapies 19:265-269.

5. Van Deusen J, Harlowe D (1987) The efficacy of the ROM Dance Program for adults with rheumatoid arthritis. Am J Occup Ther 41: 90-95.

6. Kukkonen-Harjula K (1988) More exercise for the obese? Ann Clin Res 20: $67-70$

7. Roberts D (2004) Alternative therapies for arthritis treatment: part 2. Holistic Nursing Practice 18: 167-174.

8. Minor MA, Hewett JE, Webel RR, Anderson SK, Kay DR (1989) Efficacy of physical conditioning exercise in patients with rheumatoid arthritis and osteoarthritis. Arthritis and Rheumatism 32: 1396-1405.

9. Neuberger GB, Kasal S, Smith KV, Hassanein R, DeViney S (1994) Determinants of exercise and aerobic fitness in outpatients with arthritis. Nurs Res 43: 11-17.

10. Perlman SG, Connell KJ, Clark A, Robinson MS, Conlon P, et al. (1990) Dance-based aerobic exercise for rheumatoid arthritis. Arthritis Care Res 3: 29-35.

11. Noreau L, Martineau H, Roy L, Belzile M (1995) Effects of a modified dance -based exercise on cardiorespiratory fitness, psychological state and health status of persons with rheumatoid arthritis. American Journal of Physical Medicine and Rehabilitation 74: 19-27.

12. Moffet H, Noreau L, Parent E, Drolet M (2000) Feasibility of an eightweek dance-based exercise program and its effects on locomotor ability of persons with functional class III rheumatoid arthritis. Arthritis Care Research 13: 100-111.

13. Noreau L, Moffet H, Drolet M, Parent, E (1997) Dance-based exercise program in rheumatoid arthritis. Feasibility in individuals with American College of Rheumatology functional class III disease. American Journal of Physical Medicine and Rehabilitation 76: 109-113.

14. Federici A, Bellagamba S, Rocchi MB (2005) Does dance-based training improve balance in adult and young old subjects? A pilot randomized controlled trial. Aging Clinical and Experimental Research 17: 385-389.

15. Wu WL, Wei TS, Chen SK, Chang JJ, Guo LY, et al. (2010) The effect of Chinese Yuanji-Dance on dynamic balance and the associated attentional demands in elderly adults. Journal of Sports Sciences and Medicine 9: 116-126.

16. Marks R (2015) Narrative review of dance-based exercise and its specific impact on depressive symptoms in older adults. AIMS Medical Science 3: 61-76.

17. Bojner-Horwitz E, Theorell T, Anderberg UM (2000) Dance/movement therapy and changes in stress-related hormones: a study of fibromyalgia patients with video-interpretation. The Arts in Psychotherapy 30: 255-264.

18. Kimura K, Hozuma N (2012) Investigating the acute effect of an aerobic dance exercise program on neuro-cognitive function in the elderly. Psychology of Sport and Exercise 13: 623-629.

19. Carbonell-Baeza A, Aparicio VA, Martins-Pereira CM, Gatto-Cardia CM, Ortega FB, et al. (2010) Efficacy of Biodanza for treating women with fibromyalgia. Journal Of Alternative \& Complementary Medicine 16: 1191-1200.

20. Granacher U, Muehlbauer T, Bridenbaugh SA, Wolf M, Roth R, et al. (2012) Effects of a salsa dance training on balance and strength performance in older adults. Gerontology 58: 305-312.

21. Kerwin M, Nunes F, Silva PA (2012) Dance! Don't Fall - preventing falls and promoting exercise at home. Stud Health Technol Inform 177: 254-259.

22. Ferrufino L, Bril B, Dietrich G, Nonaka T, Coubard OA (2011) Practice of contemporary dance promotes stochastic postural control in aging. Frontiers in Human Neuroscience 5: 1-9.

23. Delaney L, McVeigh G (1992) Dance away arthritis pain!. Prevention 44: 48.

24. Shigematsu R, Chang M, Yabushita N, Sakai T, Nakagaichi M, et al. (2002) Dance-based aerobic exercise may improve indices of falling risk in older women. Age and Ageing 31: 261-266.

25. Campbell PT, Werner MH, Sorenson B, Chen-Levy Z, Potter ID, et al. (2008) Effect of exercise on in vitro immune function: a 12-month randomized controlled trial among postmenopausal women. Journal of Applied Physiology 104: 1648-1655. 